\title{
PENGARUH KERAMAHAN DAN PENGETAHUAN PRODUK BEAUTY ADVISOR TERHADAP PENINGKATAN PENJUALAN POND'S DI CV. BIN WAHAB GROUP SUGIO LAMONGAN
}

\author{
Nafahatus Sahariyah \\ Siti Shoimah \\ Fakultas Ekonomi Universitas Islam Darul Ulum Lamongan \\ Email: hatusnafa1@gmail.com \\ Email: sitishoimah@unisda.ac.id
}

\begin{abstract}
This research was conducted at CV. Bin Wahab Group. This study aims to determine whether there is an influence or not from the hospitality and knowledge of beauty advisor products to increase sales of pond's both simultaneously and partially. The background of this study, the researcher chose the variable because the friendliness to the consumer variable will increase consumer confidence in the beauty advisor in explaining product knowledge that can be directed to the product being sold so as to increase sales. This research uses quantitative methods. Primary collection techniques were obtained from observations and questionnaires, while secondary data were obtained from literature studies. In determining data collection obtained from respondents through a simple random sample. The method of data analysis uses statistical tests that are operated through the SPSS 25 program. The results of partial or simultaneous test of hospitality variables and product knowledge have a positive effect on sales increase. Product knowledge has a higher influence that is if it rises by one unit, it will be followed by an increase in sales of 0.545 units compared to hospitality.
\end{abstract}

Keyword: hospitality, knowledge, beauty advisor, increase sales

\begin{abstract}
Abstrak: Penelitian ini dilakukan di CV. Bin Wahab Group. Penelitian ini bertujuan untuk mengtahuai adakah pengaruh atau tidak dari keramahan dan pengetahuan produk beauty advisor terhadap peningkatan penjualan pond's baik secara simultan maupun parsial. Latar belakang penelitian ini, penelti memilih variabel tersebut dikarenakan variabel keramahan kepada konsumen akan meningkatkan kepercayaan konsumen kepada beauty advisor dalam menjelaskan pengetahuan produk yang dapat diarahkan dengan produk yang dijual sehingga meningkatkan penjualan. penelitian ini menggunakan metode kuantitatif. Teknik pengumpulan primer diperoleh dari hasil observasi dan kuisioner, sedangkan data sekunder diperoleh dari studi kepustakaan. Dalam penentuan Pengambilan data yang diperoleh dari responden melalui sampel acak sederhana. Metode analisis data menggunakan uji stastistik yang dioperasikanmelalusi program SPSS 25. Hasil uji secara parsial maupun simultan variabel keramahan dan pengetahuan produk berpengaruh positif terhadap peningkatan penjualan. Pengetahuan produk memiliki pengaruh yang lebih tinggi yaitu jika naik sebesar satu satuan, maka akan diikuti dengan peningkatan penjualan sebesar 0,545 satuan dibandingakan dengan Kata Kunci: Keramahan, Pengetahuan, Beauty Advisor, Peningkatan Penjualan

PENDAHULUAN

Menurut CNN Indonesia, industri kecantikan Indonesia selalu

konsisten mengalami peningkatan dibanding industri lainnya. Dilihat dari fakta ini dapat dilihat
\end{abstract}




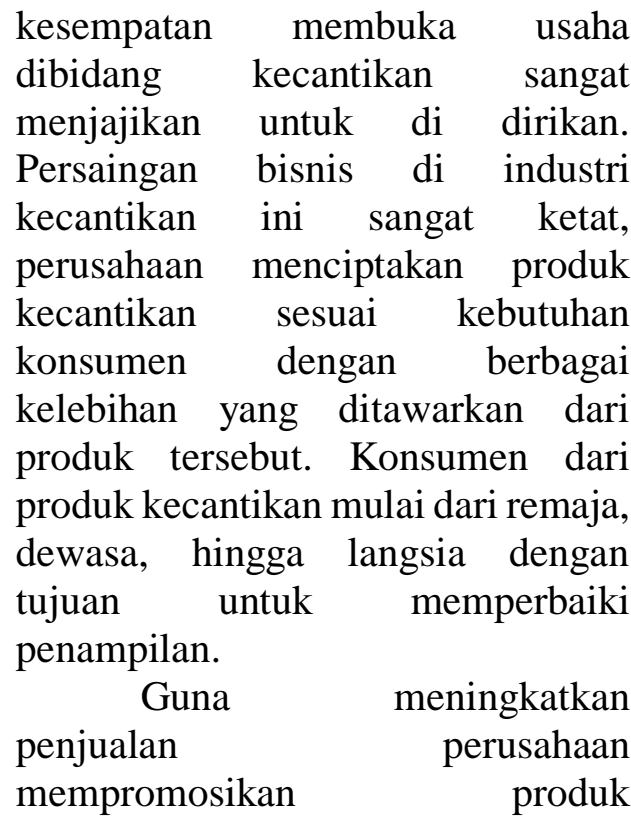
kecantikannya dengan berbagai cara seperti iklan di televisi, sosial media, banner, dan akhir-akhir ini banyak promosi lewat youtube oleh vlogger terkenal agar mempengaruhi minat seorang yang melihat videonya ingin mencoba lalu membeli produk kosmetik tersebut, juga di sertai dengan pemberian beauty advisior produk kosmetik di beberapa outlet untuk menarik perhatian dan membantu calon konsumen untuk memilih produk sesuai dengan kulit dan kebutuhan. Beauty advisor atau konsultan kecantikan adalah seseorang yang di tugaskan oleh perusahaan dengan penampilan menarik sesuai standar operasional penusahaan dimana dia bekerja dan telah dibekali pengetahuan dari perusahaan tentang kecantikan dan pengetahuan prodak (product knowledge) yang dipromosikan atau yang di jual. Pengetahuan produk didapat konsumen saat bertemu dengan beauty advisor ditoko, yang dijelaskan oleh beauty advisor dengan ramah agar mudah dimengerti konsumen. Menurut KBBI atau Kamus Besar Bahasa Indonesia Keramahan adalah sifat ramah, kebaikan hati dan keakraban (dalam bergaul). Bagian yang ini penting karena dapat berdampak pada kepuasan konsumen maupun pendekatan antara beauty advisior dengan calon konsumen. Keramahan ini guna untuk meningkatkan kedekatan dengan konsumen sehingga terjadi kepercayaan dari konsumen untuk konsultasi tentang produk yang dibutuhkan dan dapat diarahkan ke produk yang dijual sehingga dapat meningkatkan volume penjualan.

Penelitian ini dilakukan di CV. Bin Wahab Group karena disana ada banyak beauty advisor dari berbagai produk, keadaan toko ramai dan target pasar langsung ke konsumen akhir. Kemudian penelti memilih variabel Keramahan, Pengetahuan Produk dan Peningkatan penjualan dikarenakan variabel keramahan kepada konsumen akan meningkatkan kepercayaan konsumen kepada beauty advisor dalam menjelaskan pengetahuan produk yang dapat diarahkan dengan produk yang dijual sehingga dapat meningkatkan penjualan. Dan peneliti memilih variabel tersebut karena variabel tersebut menarik untuk diteliti.

\section{TINJAUAN PUSTAKA \\ Keramahan}

Menurut KBBI atau kamus besar bahasa Indonesia Keramahan adalah sifat ramah, kebaikan hati dan keakraban (dalam bergaul). bagian yang ini penting karena dapat berdampak pada kepuasan konsumen maupun pendekatan antara beauty advisior dengan calon konsumen. Dengan menunjukan adapunsikap yang ramah seorang konsumen akan lebih nyaman saat berbicara dan bertanya mengenai produk kecantikan yang akan beli. 
Menurut Kuswara Heri (2009) dalam Wibowo (2011:6) Ramah adalah sikap santun terhadap semua orang agar orang lainmerasakan kenyamanan dan perasaan senang saat bersama kita. Bersikap ramah dan baik ternyata belum cukup bagikaryawan dalam menjalankan tugasnya. Sikap dan perilaku dalam dunia bisnisjuga menjadi salah satu faktor untuk mengembangkan dan memajukan usaha. Adapun perilaku dan sikap yang harus dilakukan, baik itu oleh pengusaha ataupun oleh karyawan adalah sebagai berikut :

1. Jujur dalam bertindak dan bersikap Suatu sikap yang jujur merupakan modal utama untuk melayani pelanggan. Dengan kejujuran inilah yang akan dapat menumbuhan kepercayaan dari konsumen terhadap pelayanan yang diberikan

2. Rajin, tepat waktu dan tidak malas

Sifat ini harus dimiliki oleh seorang pengusaha dan para karyawannya dalam melayani konsumen atau pelanggan. Selain itu mereka juga dituntut untuk cekatan dalam bekerja, pantang menyerah, selalu ingin tahu, tidak mudah putus asa serta tidak memiliki sifat malas..

3. Selalu murah senyum

Dengan tersenyum, akan lebih mudah bagi karyawan dalam membujuk pelanggan agar ia menyukai produk atau perusahaan. Para pelanggan biasanya akan tersanjung dan merasa dihargai dengan senyum yang ditunjukan karyawan.

4. Lemah lembut dan ramah tamah

Pada saat berbicara kepada pelanggan ada baiknya dengan suara yang lemah lembut yang didukung dengan sikap ramah. Sikap seperti itu Pada saat berbicara dengan para pelanggan, ada baiknya dengan suara yang lemah lembut yang didukung oleh sikap ramah. Sikap seperti itu, dapat menarik minat dari tamu atau konsumendan membuat pelanggan betah berhubungan dengan karyawan atau perusahaan.

5. Sopan santun dan hormat

Dalam memberikan suatu pelayanan kepada pelanggan hendaknya selalu dengan sopan dan hormat. Dengan demikian, pelanggan juga akan menghormati pelayanan yang diberikan karyawan tersebut.

6. Selalu ceria dan pandai bergaul

Sikap yang seperti ini akan memecahkan kekakuan yang ada. Dengan sikap pandai bergaul, pengusaha atau karyawan akan cepat akrab dengan pelanggan sehingga diharapkan segala urusan lebih lancar.

7. Fleksibel dan suka menolong pelanggan

Dalam menghadapi pelanggan, karyawan harus dapat memberi pengertian. Selain itu, juga diiharapkan dapat memberikan pertolongan kepada pelanggan yang engalami kesulitan. .

8. Serius dan memiliki rasa tanggung jawab

Dalam melayani pelanggan, pengusaha atau karyawan harus melakukannya dengan serius dan dengan sepenuh hati. Mereka juga harus tanggung jawab terhadap pekerjaan agar pelanggan merasa puas terhadap pelayanan yang diberikan.

9. Rasa memiliki perusahaan yang tinggi

Perusahaan dan karyawan harus merasa memiliki setiap unsur perusahaan. Dengan sikap seperti itu, diharapkan untuk setiap pihak dapat termotivasi dalam berusaha mengembangkan dan memajukan 
perusahaan. Selain sifat tersebut, pemilik dan karyawan juga diharapkkan memiliki jiwa pengabdian, loyal, dan setia kepada perusahaan..

10. Gunakan norma-norma agama, setiap agama memiliki aturan yang difirmankan tuhan.

\section{Pengetahuan Produk}

Menurut Nitisusatro (2012) dalam Hanjaya Sanny (2016:183) hal yang terkait dengan pengetahuan produk adalah pengetahuan tentang karakteristik produk, pengetahuan tentang manfaat produk, pengetahuan tentang resiko mengkonsumsi produk dan pengetahuan tentang kepuasan mengkonsumsi produk.

Pengetahuan produk adalah kumpulan dari berbagai informasi mengenai produk tersebut. Pengetahuan ini meliputi kategori produk, merek, terminologi produk, atributataufitur produk, harga produk dan kepercayaan mengenai produk.

Menurut Hoyer dan Maclnnis (1997) Dalam Novianty Esther (2017:9), pengetahuan produk bisa didapat dari produk itu sendiri ataupun dari pengalaman penggunaan prpeter oduk, seperti periklanan, interaksi dengan tenaga penjual, informasi dari teman atau media, pengambilan keputusan yang sebelumnyaatau penggunaan produk,dan ingatan konsumen.

\section{Beauty Advisor (BA)}

Beauty advisor atau konsultan kecantikan adalah seseorang yang di tugaskan oleh perusahaan dengan penampilan menarik sesuai standar operasional penusahaan dimana dia bekerja dan telah dibekali pengetahuan dari perusahaan tentang kecantikan dan pengetahuan prodak (product knowledge) yang dipromosikan atau yang di jual.

Peningkatan Penjualan
Menurut Mulyadi (2005) dalam Sriyanto (2015:7) volume penjualan merupakan ukuran yang menunjukan banyaknya atau besarnya jumlah barang atau jasa yang terjual. Sehingga volume penjualan merupakan jumlah total yang dihasilkan dari penjualan barang. Semakin tinggi penjualan barang perusahaan maka menunjukkan tingkat keberhasilan suatu perusahaan dalam melakukan upaya pengembangan pada perusahaan dan semakin tinggi laba yang dihasilkan.

\section{Kerangka Konsepual}

Berdasarkan tinjauan pustaka yang telah dikemukakan sebelumnya, dalam penelitian ini peneliti akan meneliti pengaruh keramahan dan pengetahuan produk terhadap peningkatan penjualan ponds di CV. Bin Wahab group Sugio Lamongan'

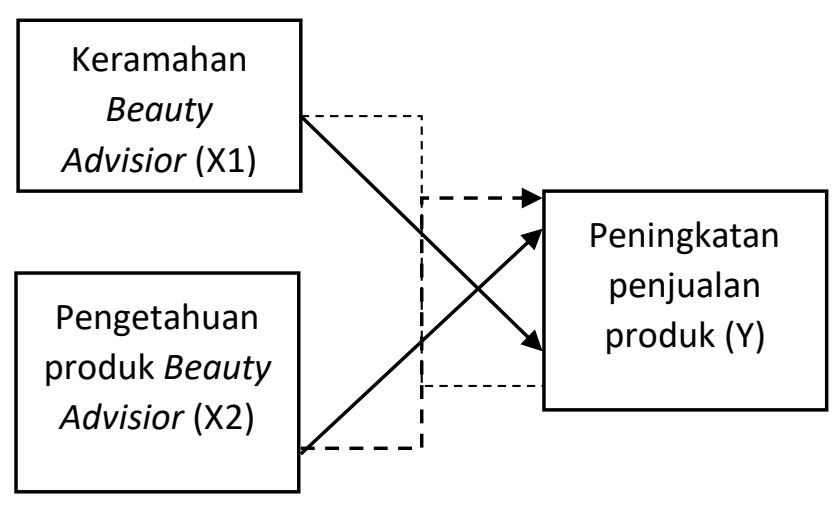

Gambar Kerangka Konsepsual

\section{METODE PENELITIAN \\ Pendekatan Penelitian}

Penelitian ini penelitian kuantitatif menggunakan pendekatan penelitian deskriptif. Menurut ciri atau sifat metode (penelitian) survei antara lain adalah bahwa biasanya informasi dikumpulkan dari responden dengan menggunakan kuesioner, dan tidak seperti dalam penelitian sensus yang menggunakan seluruh populasi, dalam penelitian survei informasi dikumpulkan 
dari sampel yang di anggap dapat mewakili seluruh populasi.

\section{Populasi, Sampel dan Teknik Pengambilan Sampel}

Populasi

Dalam Soewadji Jusuf (2012:129) Populasi adalah sekelompok unsur atau elemen yang dapat berbentuk manusia atau individu, binatang, tumbuh - tumbuhan, lembaga atau institusi, kelompok, dokumen, kejadian, sesuatu hal, gejala, atau berbentuk konsep yang menjadi objek penelitian. Populasi yang digunakan dalam penelitian ini adalah konsumen dari produk pond's yang di laksanakan di bulan mei di CV. Bin Wahab group Sugio Lamongan yang berjumlah kurang lebih 600 orang pada bulan tersebut.

Sampel

Sugiyono

(2018:131)

mendefinisikan bahwa sampel adalah sebagian dari jumlah dan karakterstik yang dimiliki oleh populasi tersebut. Bila populasinya besar, dan peneliti tidak mungkin mempelajari semua yang ada di populasi, misal karena keterbatasan tenaga dan waktu, maka peneliti dapat menggunakan sampel yang diambil dari populasi itu. Untuk itu sampel yang diambil dari populasi harus dapat mewakili.

Teknik Pengambilan Sampel

\section{HASIL DAN PEMBAHASAN}

Uji Kualitas Data

Dari yang sudah dijelaskan oleh peneliti tentang pengujian dibab sebelumnya yaitu metode analisis data, berikut ini hasil yang sudah diperoleh:

1. Uji Validitas

Uji validitas merupakan suatu tolak ukur yang menunjukan tingkat kevalidan suatu data atau instrumen, intrumen yang sahih atau valid mempunyai validitas yang tinggi. Sebaliknya, instrument yang validitasnya rendah berarti instrumen datanya kurag valid. Intrumen dikatakan valid apabila bias mengungkapkan data dari variabel yang di teliti secara tepat. Uji validitas dilaksanakan dengan dasar pertanyaan menggunakan faktor analisis terhadap setiap poin pertanyaan atau pernyataan. Uji validitas dilakukan dengan pertanyaan yang dimuat dikuisioner kepada responden dan di uji dengan bantuan program atau aplikasi SPSS (Statistical package for social). Uji validitas ini akan memenuhi syarat jika benar dapat mengidikasikan variabel, maka nilai loading faktor dan KOM MSA akan tinggi > 0,05, dengan dergree of freedom $(\mathrm{df})=\mathrm{n}-\mathrm{k}$ denagan alpha 0,05. Atau jika nilai r-hitung > rtabel maka variabel tersebut dapat dikatakan valid. Berikut ini adalah hasil dari perhitungan uji validitas dengan menggunakan perhitungan deprogram SPSS:

Tabel Hasil Uji Validitas Keramahan

\begin{tabular}{|c|c|c|c|c|}
\hline Variabel & Item & $\begin{array}{c}\text { Nilai r } \\
\text { hitung }\end{array}$ & $\begin{array}{c}\text { Nilai r } \\
\text { tabel }\end{array}$ & Keputusan \\
\hline \multirow{4}{*}{$\begin{array}{c}\text { Keramahan } \\
(\text { X1) }\end{array}$} & $\mathrm{X} 1.1$ & 0,626 & 0,2120 & Valid \\
\cline { 2 - 5 } & $\mathrm{X} 1.2$ & 0,716 & 0,2120 & Valid \\
\cline { 2 - 5 } & $\mathrm{X} 1.3$ & 0,671 & 0,2120 & Valid \\
\cline { 2 - 5 } & $\mathrm{X} 1.4$ & 0,646 & 0,2120 & Valid \\
\cline { 2 - 5 } & $\mathrm{X} 1.5$ & 0,645 & 0,2120 & Valid \\
\cline { 2 - 5 } & $\mathrm{X} 1.6$ & $0,390 \mathrm{c}$ & 0,2120 & Valid \\
\cline { 2 - 5 } & $\mathrm{X} 1.7$ & 0,538 & 0,2120 & Valid \\
\cline { 2 - 5 } & $\mathrm{X} 1.8$ & 0,512 & 0,2120 & Valid \\
\hline
\end{tabular}

2020

Tabel Hasil Uji Validitas

Pengetahuan Produk

\begin{tabular}{|c|c|c|c|c|}
\hline \multirow{4}{*}{ Variabel } & Item & $\begin{array}{c}\text { Niai r } \\
\text { hitun } \\
\mathbf{g}\end{array}$ & $\begin{array}{c}\text { Nilai } \\
\mathbf{r} \\
\text { tabel }\end{array}$ & $\begin{array}{c}\text { Keputusa } \\
\mathbf{n}\end{array}$ \\
\hline \multirow{4}{*}{$\begin{array}{c}\text { Pengetahua } \\
\text { n Poduk } \\
\text { (X2) }\end{array}$} & $\mathrm{X} 2.1$ & 0,412 & $\begin{array}{c}0,212 \\
0\end{array}$ & Valid \\
\cline { 2 - 6 } & $\mathrm{X} 2.2$ & 0,542 & $\begin{array}{c}0,212 \\
0\end{array}$ & Valid \\
\cline { 2 - 5 } & $\mathrm{X} 2.3$ & 0,615 & $\begin{array}{c}0,212 \\
0\end{array}$ & Valid \\
\cline { 2 - 5 } & $\mathrm{X} 2.5$ & 0,442 & $\begin{array}{c}0,212 \\
0\end{array}$ & Valid \\
\cline { 2 - 5 } & $\mathrm{X} 2.6$ & 0,383 & $\begin{array}{c}0,212 \\
0\end{array}$ & Valid \\
\cline { 2 - 5 } & $\mathrm{X} 2.7$ & 0,455 & $\begin{array}{c}0,212 \\
0\end{array}$ & Valid \\
\cline { 2 - 5 } & $\mathrm{X} 2.8$ & 0,441 & $\begin{array}{c}0,212 \\
0\end{array}$ & Valid \\
\hline
\end{tabular}




\begin{tabular}{|c|c|c|c|c|}
\hline & X2.9 & 0,648 & $\begin{array}{c}0,212 \\
0\end{array}$ & Valid \\
\cline { 2 - 5 } & $\begin{array}{c}\text { X2.1 } \\
0\end{array}$ & 0,534 & $\begin{array}{c}0,212 \\
0\end{array}$ & Valid \\
\cline { 2 - 5 } & $\begin{array}{c}\text { X2.1 } \\
1\end{array}$ & 0,513 & $\begin{array}{c}0,212 \\
0\end{array}$ & Valid \\
\hline
\end{tabular}

Sumber : data primer diolah 2020

Tabel Hasil Uji Validitas

Peningkatan

\begin{tabular}{|c|c|c|c|c|}
\hline Variabel & Item & $\begin{array}{c}\text { Nilai } \mathbf{r} \\
\text { hitung }\end{array}$ & $\begin{array}{c}\text { Nilai } \mathbf{r} \\
\text { tabel }\end{array}$ & Keputusan \\
\hline \multirow{4}{*}{$\begin{array}{c}\text { Peningkatan } \\
\text { (Y) }\end{array}$} & Y.1 & 0,661 & 0,2120 & Valid \\
\cline { 2 - 5 } & $Y .2$ & 0,666 & 0,2120 & Valid \\
\cline { 2 - 5 } & $Y .3$ & 0,689 & 0,2120 & Valid \\
\cline { 2 - 5 } & $Y .4$ & 0,614 & 0,2120 & Valid \\
\cline { 2 - 5 } & Y.5 & 0,561 & 0,2120 & Valid \\
\hline
\end{tabular}

Sumber : data primer diolah 2020

Hasil dari perhitungan uji validitas pada tabel tersebut didasari oleh perbandingan antara nilai dari r-hitung dan nilai $\mathrm{r}$-tabel, dimana $\mathrm{r}$-tabel $=(\mathrm{df}=$ $\mathrm{n}-\mathrm{k}, 86-2=84$ pada $\alpha=0,5)$ adalah 0,2120 . Dapat dikatakan bahwa pada tabel uji validitas tersebut, nilai r-hitung $>$ r-tabel atau nilai KMO MSA > 0,05. Oleh karena itu dapat disimpulkan bahwa semua angket dari variabel penelitian ini adalah valid. Sehingga dapat di gunakan sebagai instrument penelitian.

2. Uji Reliabilitas

Uji reabilitas merupakan alat untuk mengukur kuesioner, dimana kuesioner tersebut adalah indikator dari variabel. Kuesioner akan dikatakan reliabel jika jawaban responden terhadap pertanyaan adalah konsisten dan stabil dari waktu ke waktu, pengujian ini akan dilakukan dengan program SPSS. Poin pertanyaan yang telah dikatakan valid oleh atau dalam pengujian di uji validitas, ditentukannya reabilitas dengan syarat atau kriteria sebagai berikut: jika nilai (Cronbach's Alpha) > 0,60 berarti kuesioner tersebut di nyatakan reliabel dan siap untuk digunakan sebagai instrumen dalam penelitian.

Tabel Hasil Uji Reabilitas

\begin{tabular}{|c|c|c|}
\hline Variabel & $\begin{array}{c}\text { Cronbach's } \\
\text { Alpha }\end{array}$ & Keterangan \\
\hline Keramahan (X1) & 0,740 & Reliabel \\
\hline $\begin{array}{c}\text { Pengetahuan } \\
\text { Produk (X2) }\end{array}$ & 0,675 & Reliabel \\
\hline Peningkatan (Y) & 0,629 & Reliabel \\
\hline
\end{tabular}

2020

Sumber : Data primer diolah

Dari tabel tersebut nilai Cronbach's Alpha untuk dari tabel tersebut nilai Cronbach's Alpha Untuk variable bebas dan terikatnya yaitu keramahan, pengetahuan produ dan kinerja $>0,60$ dengan tingkat signifikan $\alpha=5 \%$ sehingga dapat di simpulkan bahwa instrument untuk variabel bebas dan variabel terikatnya yaitu reliabel.

3. Uji Regresi Linier Berganda

Analisis regresi linier berganda untuk mengetahuai sebesar apa pengaruh keramahan dan pengetahuan produk beauty advisor terhadap peningkatan penjualan. Analisi ini menggunakan program SPSS dengan perolehan sebagai berikut

Tabel Uji Regresi Linier Berganda

\begin{tabular}{|c|c|c|c|c|c|c|}
\hline \multicolumn{7}{|c|}{ Coefficients $^{\mathrm{a}}$} \\
\hline & \multirow[t]{2}{*}{ Model } & \multicolumn{2}{|c|}{$\begin{array}{l}\text { Unstandardized } \\
\text { Coefficients }\end{array}$} & \multirow{2}{*}{$\begin{array}{c}\begin{array}{c}\text { Standar } \\
\text { dized } \\
\text { Coeffic } \\
\text { ients }\end{array} \\
\text { Beta }\end{array}$} & \multirow[t]{2}{*}{$\mathrm{t}$} & \multirow[t]{2}{*}{ Sig. } \\
\hline & & B & $\begin{array}{l}\text { Std. } \\
\text { Error }\end{array}$ & & & \\
\hline \multirow{3}{*}{1} & (Constant) & 2,259 & 2,469 & & 0,915 & 0,363 \\
\hline & $\mathrm{X} 1$ & 0,140 & 0,060 & 0,214 & 2,340 & 0,022 \\
\hline & $\mathrm{X} 2$ & 0,313 & 0,053 & 0,540 & 5,923 & 0,000 \\
\hline \multicolumn{7}{|c|}{ a. Dependent Variable: $\mathrm{Y}$} \\
\hline
\end{tabular}

Sumber : data Output IBM spss versi 25

Analisis:

Dari tabel diatas menunjukan data dari regresi linier berganda di peroleh persamaan sebagai berikut: $Y=2,259+0,140+0,313+2,469$

a. Konstanta $(\alpha)$

$\alpha=2,259$ mengandung pengertian bahwa perpotongan garis regresi pada variabel bebas (X1, X2) Nilai 2,259 juga berarti bahwa jika 
beauty advisor tidak memiliki sikap keramahan dan pengetahuan produk maka CV.Bin Wahab group masih meraih kinerja beauty advisor sebesar 2,259 satuan.

b. Keramahan (X1) terhadap Peningkatan Penjualan

$$
\beta 1=0,140 \text { nilai ini mengandung }
$$

pengertian bahwa apabila X1 (Keramahan) naik sebesar satu satuan,maka akan diikuti peningkatan penjualan sebesar 0,140 satuan. Dengan asumsi bahwa variabel keramahan (X2) konstan.

c. Kesehatan kerja(X2) Terhadap Kinerja karyawan

$$
\beta 2=0,313 \text { nilai mengandung }
$$
pengertian bahwa apabila X2 (Pengetahuan produk), naik sebesar satu satuan maka diikuti oleh peningkatan penjualan sebesar 0,313 satuan. Dengan asumsi variabel keselamatan kerja (X1) konstan.

Dari hasil koefisien variabel bebas diatask keduanya bernilai positif. Hal ini berarti mempunyai arah perubahan yang searah dengan variabel terikat. Koefisien regresi variabel pengetahuan produk 0,313 dengan standar koefisien beta sebesar 0,540 nilai paling besar dari pada variabel keramahan. Dengan demikian dapat ditarik kesimpulan bahwa faktor yang dominan mempengaruhi peningkatan penjualan adalah pengetahuan produk.

4. Uji Asumsi Klasik

Uji ini bertujuan agar kita dapat menguji suatu kelayakan model regresi yang dipakai dalam penelitian.

a. Uji Multikolinieritas

Uji multikonieritas bertujuan guna menguji model regresi tersebut apakah ditemukan adanya korelasi atau hubungan antar independen variabel bebas. Model regresi yang dikatakan baik jika tidak terjadi kolerasi atau hubungan antar variabel bebas (independen) dan variabel tersebut tidak orthogonal. Variabel orthogonal yaitu variabel bebas dengan nilai korelasi antara variabel bebas $=0$, multikolineritas dilihat dari nilai Tolerance $\geq 0,10$ dan Inflation Factor (VIF) $\leq 10$ menunjukan bahwa korelasi antar variabel independent tidak terjadi multikolinearitas.

\begin{tabular}{|c|c|c|c|c|c|c|c|}
\hline \multicolumn{8}{|c|}{ Coefficients $^{\mathbf{a}}$} \\
\hline \multirow[b]{2}{*}{ Model } & \multicolumn{2}{|c|}{$\begin{array}{l}\text { Unstandardized } \\
\text { Coefficients }\end{array}$} & \multirow{2}{*}{ 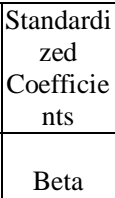 } & \multirow[b]{2}{*}{$\mathrm{t}$} & \multirow[b]{2}{*}{ Sig. } & \multicolumn{2}{|c|}{$\begin{array}{c}\text { Collinearity } \\
\text { Statistics }\end{array}$} \\
\hline & $\mathrm{B}$ & $\begin{array}{l}\text { Std. } \\
\text { Error }\end{array}$ & & & & $\begin{array}{c}\text { Toleran } \\
\text { ce }\end{array}$ & VIF \\
\hline \begin{tabular}{|l|l}
1 & (Constant) \\
\end{tabular} & 2.259 & 2.469 & & .915 & .363 & & \\
\hline $\mathrm{X} 1$ & .140 & .060 & .214 & 2.340 & .022 & .815 & 1.227 \\
\hline $\mathrm{X} 2$ & .313 & .053 & .540 & 5.923 & .000 & .815 & 1.227 \\
\hline
\end{tabular}

Tabel Uji Multikolinearitas

Sumber: data Output IBM spss versi 25

Dari tabel di atas menunjukkan bahwa nilai VIF dari semua variabel bebas dalam penelitian ini lebih kecil dari 10, sedangkan nilai tolerancesemua variabel bebas lebih dari $10 \%(0,10)$, berarti tidak terjadi korelasi antara variabel bebas. Dengan demikian dapat di simpulkan bahwa tidak terdapat gejala multikolonieritas antar variabel bebas dalam model regresi.

b. Uji Autokorelasi

Uji autokorelasi dalam suatu penelitian berguna untuk mengetahui apakah ada korelasi antara variabel pengganggu pada periode tertentu dengaan variabel sebelumnya untuk data time series autokorelasi sering terjadi. Namun data untuk sampel crossection jarang terjadi disebabkan variabel pengganggu satu berbeda dengan yang lainnya. Mendeteksi autokorelasi dengan menggunakan Durbin Waston (DW) hitung dengan Durbin Waston tabel, yaitu batas atas (dU) dan batas bawah (dL). Pengujian autokorelasi menggunakan SPSS dengan versi 25. Untuk kriteria pengujian adalah berikut ini : 
a) Jika DW, dL atau > (4- dL) maka hipotesis 0 ditolak, yang berarti terdapat autokorelasi.

b) Jika DW, dU atau > (4- dU) maka

\begin{tabular}{|c|c|c|c|c|c|}
\hline \multicolumn{6}{|c|}{ Model Summary ${ }^{b}$} \\
\hline Model & $\mathrm{R}$ & $\begin{array}{c}\mathrm{R} \\
\text { Square }\end{array}$ & $\begin{array}{c}\text { Adjusted } \\
\text { R } \\
\text { Square }\end{array}$ & $\begin{array}{c}\text { Std. } \\
\text { Error of } \\
\text { the } \\
\text { Estimate }\end{array}$ & $\begin{array}{l}\text { Durbin- } \\
\text { Watson }\end{array}$ \\
\hline 1 & $.661^{\mathrm{a}}$ & 0,437 & 0,423 & 1,015 & 2,222 \\
\hline \multicolumn{6}{|c|}{ a. Predictors: (Constant), X2, X1 } \\
\hline b. Depe & Varia & & & & \\
\hline
\end{tabular}

hipotesis 0 diterima, yang berarti tidak terdapat autokorelasi.

c) Jika DW terletak antara dan diantara (4dU) dan (4- dL), maka tidak bisa menghasilkan kesimpulan yang pasti.

Tabel Uji Autokorelasi

Sumber : data Output IBM spss versi 25

Dari tabel pengujian dengan menggunakan uji Durbin Watson (DW) atas residual persamaan regresi diperoleh angka d-hitung sebesar 2,222, sedangkan dari tabel Durbin Watson (DW) dengan signifikan 0,05, di peroleh nilai $\mathrm{dL}=1,602$ dan nilai $\mathrm{dU}=1,697$.

Karena nilai DW $(2,222)$ berada pada daerah diantara dU $(1,697)$ dan 4dU (2,303), dan DW juga berada pada daerah dL(1,602) dan 4-dL (2,398) sehingga dapat disimpulkan bahwa tidak bisa menghasilkan kesimpulan yang pasti.

c. Uji Heteroskedastisitas

Uji Heteroskedastisitas memiliki tujuan untuk menguji apakah model regresi ini terjadi ketidaksamaan variance dari residual satu pengamatan ke pengamatan lainnya. Apabila jika variance dari residual satu pengamatan ke pengamatan lainnya tetap, maka disebut homoskedastisitas dan jika variance berbeda disebut heteroskedastisitas.

a) Jika ada pola tertentu, seperti titik-titik yang ada dan membentuk sebuah pola tertentu yang teratur (bergelombang, melebar kemudia menyempit) maka mengindikasikan telah terjadi heteroskadastisitas.

b) Jika tidak ada pola yang jelas dan titik titiknya menyebar diatas dan dibawah angka pada sumbu 0 pada sumbu Y, maka menunjukan bahwa tidak terjadi heteroskadastisitas.

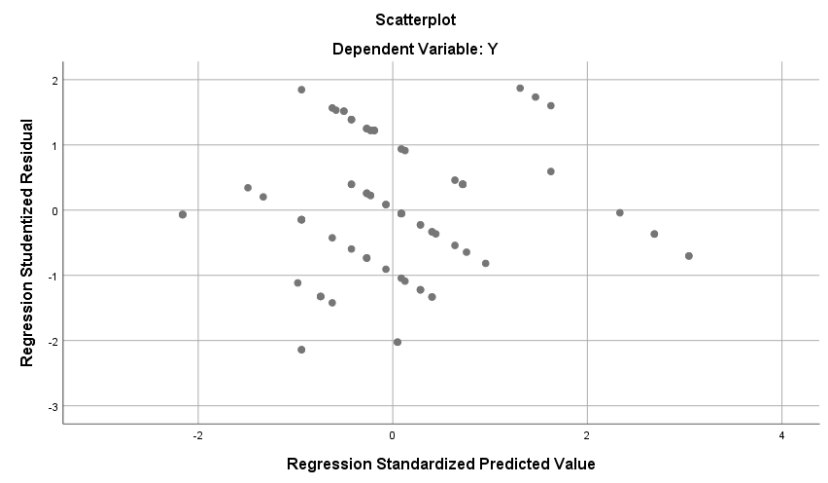

Gambar Heteroskedastisitas

Dari gambar Scatterplot Dependent variable di atas dapat di lihat titik-titik tidak terdapat pola tertentu, serta titik-titik menyebar di atas dan di bawah angka nol pada sumbu Y, maka tidak terjadi heteroskedastisitas atau terjadi Homoskedastisitas.

d. Uji Normalitas

Uji normalitas untuk menguji apakah dalam model regresi, variabel pengganggu atau residual memiliki distribusi normal. Suatu model regresi yang baik adalah yang memiliki distribusi data normal atau mendekati normal. Dasar pengambilan keputusan adalah:

a) Jika data (titik) menyebar pada sekitar garis diagonal dan mengikuti arah dari garis diagonal maka model regresi telah memenuhi asumsi normalitas

b) Jika data (titik) menyebar jauh dari garis diagonal dan tidak mengikuti arah garis diagonal, maka model regresi tidak memenuhi asumsi normalitas. 
Humanis Vol. 12 No. 2

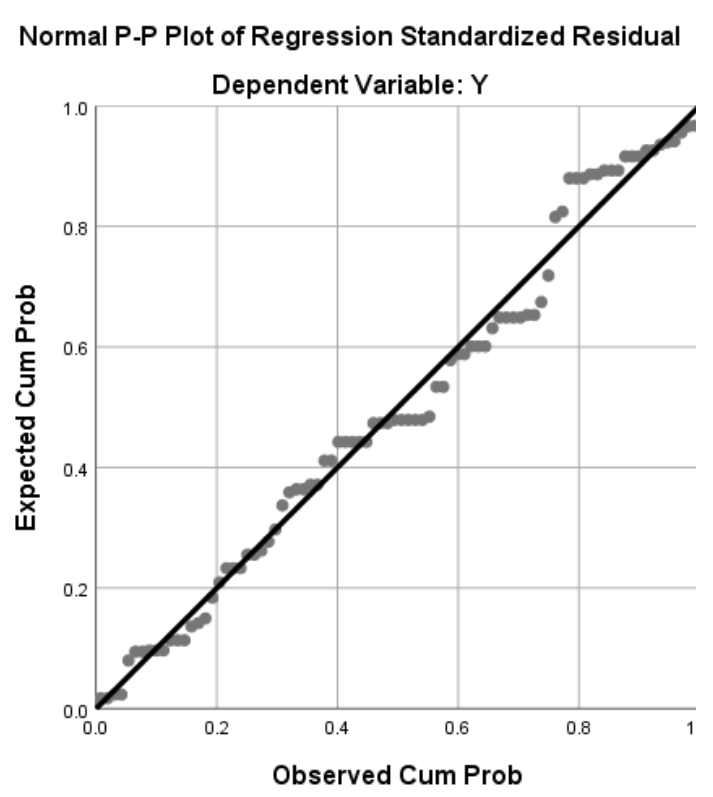

Gambar Uji Normalitas

Dari gambar Normal P-P Plot

Dependent Variable terlihat titik-titik menyebar disekitar garis diagonal dan mengikuti arah garis diagonal, maka model regresi memenuhi asumsi normalitas

5. Uji Hipotesis

Uji hipotesis digunakan untuk menilai ketepatan dari suatu fungsi regresi.

a. Uji F (Uji Simultan)

Uji F signifikan model regresi secara simultan di uji dengan melihat nilai signifikan dimana jikalau nilai dari sig dibawah 0,05 maka variabel tersebut independen. Untuk dasar pengambilan keputusan dengan menggunakan angket probabilitas signifikasi, yaitu:

a) Jika nilai tingkat signifikan $F>0,05$ atau $\mathrm{F}$ hitung < $\mathrm{F}$ tabel, maka $\mathrm{H}_{0}$ akan diterima dan $\mathrm{H}_{1}$ ditolak.

b) Jika nilai tingkat signifikan $\mathrm{F}<0,05$ atau $\mathrm{F}$ hitung $>\mathrm{F}$ tabel, maka $\mathrm{H}_{0}$ akan ditolak dan $\mathrm{H}_{1}$ diterima.

Tabel Uji F (Simultan)

\begin{tabular}{|c|c|c|c|c|c|c|}
\hline \multicolumn{7}{|c|}{ ANOVA $^{a}$} \\
\hline \multicolumn{2}{|c|}{ Model } & $\begin{array}{l}\text { Sum of } \\
\text { Squares }\end{array}$ & Df & $\begin{array}{l}\text { Mean } \\
\text { Square }\end{array}$ & F & Sig. \\
\hline \multirow[t]{3}{*}{1} & Regression & 66,406 & 2 & 33,203 & 32,214 & $.000^{\mathrm{b}}$ \\
\hline & Residual & 85,547 & 83 & 1,031 & & \\
\hline & Total & 151,953 & 85 & & & \\
\hline \multicolumn{7}{|c|}{ a. Dependent Variable: $\mathrm{Y}$} \\
\hline \multicolumn{7}{|c|}{ b. Predictors: (Constant), X2, X1 } \\
\hline
\end{tabular}

Sumber : data Output IBM spss versi 25

Pengujian pengaruh variabel bebas secara bersama-sama terhadap variabel terikatnya dilakukan dengan menggunakan uji F. Hasil perhitungan menunjukkan nilai $\mathrm{F}$ hitung $=32,214$. Dengan signifikan 0,000 , maka di peroleh nilai signifikasi tersebut lebih kecil dari 0,05. Dengan df pembilang $=2$ dan df penyebut $=83$ didapatkan Ftabel 3,11 . Hal ini berarti hipotesis yang menyatakan bahwa variabel keramahan dan pengetahuan produk secara simultan memiliki pengaruh terhadap peningkatan penjualan.

b. Uji T (Uji Parsial)

Uji T atau yang biasa dikenal dan disebut uji signifikan terhadap masing-masing koefisien regresi untuk mengetahui signifikan atau tidaknya pengaruh masing-masing variabel bebas terhadap variabel terikat (Y) .

Dasar untuk pengambilan keputusan adalah dengan menggunakan angka signifikansi yaitu:

a) Jika tingkat signifikansi t hitung $>0,05$ atau $\mathrm{t}$ hitung $<\mathrm{t}$ tabel, maka $\mathrm{H}_{0}$ diterima dan $\mathrm{H}_{1}$ ditolak.

b) Jika tingkat signifikansi t hitung $<0,05$ atau $\mathrm{t}$ hitung $>\mathrm{t}$ tabel, maka $\mathrm{H}_{0}$ ditolak dan $\mathrm{H}_{1}$ diterima.

Tabel Uji T (Parsial)

\begin{tabular}{|c|c|c|c|c|c|c|}
\hline \multicolumn{7}{|c|}{ Coefficients $^{\mathrm{a}}$} \\
\hline \multirow{2}{*}{\multicolumn{2}{|c|}{ Model }} & \multicolumn{2}{|c|}{$\begin{array}{l}\text { Unstandardized } \\
\text { Coefficients }\end{array}$} & \multirow{2}{*}{$\begin{array}{c}\text { Standardized } \\
\text { Coefficients } \\
\text { Beta }\end{array}$} & \multirow[b]{2}{*}{$\mathrm{T}$} & \multirow[b]{2}{*}{ Sig. } \\
\hline & & B & $\begin{array}{c}\text { Std. } \\
\text { Error }\end{array}$ & & & \\
\hline 1 & (Constant) & 2,259 & 2,469 & & 0,915 & 0,363 \\
\hline & $\mathrm{X} 1$ & 0,140 & 0,060 & 0,214 & 2,340 & 0,022 \\
\hline & $\mathrm{X} 2$ & 0,313 & 0,053 & 0,540 & 5,923 & 0,000 \\
\hline
\end{tabular}

Sumber : data Output IBM spss versi 25 
a) Nilai $\mathrm{T}$ hitung dari keramahan (X1) terhadap kinerja karyawan sebesar 2,340 sementara untuk $\mathrm{T}$ tabel degan taraf signifikan $\mathrm{a}=0,05(0,05 / 2=0,025)$ dan df = n-k-1, yaitu 86-2-1= 83 sebesar 1,988, maka di dapat $\mathrm{T}$ tabel satu sisi sebesar 1,988 dikarenakan nilai $\mathrm{T}$ hitung $>\mathrm{T}$ tabel, hal ini menunjukkan bahwa diterimanya $\mathrm{H} 1$ yang menyatakan ada pengaruh positif variable keramahan terhadap peningkatan penjualan.

b) Nilai $\mathrm{T}$ hitung dari pengetahuan produk (X2) terhadap peningkatan penjualan sebesar 5,923 sementara untuk $\mathrm{T}$ tabel dengan taraf signifikan a $=0,05(0,05 / 2$ $=0025)$ dan $\mathrm{df}=\mathrm{n}-\mathrm{k}-1$, yaitu $86-2-1=83$ sebesar 1,988, maka di dapat T tabel satu sisi sebesar 1,988 dikarenakan $\mathrm{T}$ hitung $>\mathrm{T}$ tabel, hal ini menunjukan bahwa diterimanya $\mathrm{H} 1$ yang menyatakan ada pengaruh positif variabel pengetahuan produk.

\section{Pebahasan}

Jawaban atau hasil dari pengelolaan data dan analisis yang telah dilakukan oleh peneliti dengan menggunakan program SPSS 25 dapat dipastikan kuesioner yang telah di sebarkan kepada responden oleh peneliti valid dengan hasil sebagai berikut:

\section{Uji Validitas}

1. Nilai $r$ hitung variabel keramahan (X1) pada item X1.1 sebesar 0,626, item X1.2 sebesar 0,716, item X1.3 sebesar 0,671, item X1.4 sebesar 0,646, item X1.5 sebesar 0,645, Item X1.6 sebesar 0,390, item X1.7 sebesar 0,538, item X1.8 sebesar 0,512. Dari hasil tersebut dapat dipastikan kalau variabel tersebut layak untuk dianalisis lebih lanjut.

2. Nilai $r$ hitung variabel pengetahuan produk (X2) pada item X2.1 sebesar 0,412 , item X2.2 sebesar 0,542 , item X2.3 sebesar 0,615 , item X2.4 sebesar 0,491 , item X2.5 sebesar 0,442 , item X2.6 sebesar 0,383 , item X2.7 sebesar 0,455 , item X2.8 sebesar 0,441 , item X2.9 sebesar 0.648 , item X2.10 sebesar
0,534, item X2.11 sebesar 0,513. Dari hasil tersebut dapat dipastikan kalau variabel tersebut layak untuk dianalisis lebih lanjut.

3. Nilai $r$ hitung variabel peningkatan penjualan (Y) pada item Y.1 sebesar 0,661, item Y.2 sebesar 0,666, item Y.3 sebesar 0,689, item Y.4 sebesar 0,614, item Y.5 sebesar 0,561. Dari hasil tersebut dapat dipastikan bahwa variabel tersebut layak untuk dianalisi lebih lanjut.

\section{Uji Realibilitas}

1. Nilai Crondbach's alpha variabel keramahan (X1) sebesar 0,740, dengan kesimpulan bahwa variabel keramahan dinyatakan reliabel karena 0,740 >0,60. Sehingga layak untuk dianalisi lebih lanjut.

2. Nilai Crondbach's alpha variabel pengetahuan produk (X2) sebesar 0,689, dengan kesimpulan bahwa variabel pengetahuan produk dinyatakan reliabel karena $0,675>0,60$. Sehingga layak untuk dianalisi lebih lanjut.

3. Nilai Crondbach's alpha variabel peningkatan penjualan (Y) sebesar 0,629, dengan kesimpulan bahwa variabel peningkatan penjualan dinyatakan reliabel karena 0,629>0,60. Sehingga layak untuk dianalisis lebih lanjut.

Uji regresi linier berganda

$$
\mathrm{Y}=2,259+0,140+0,313+2,469
$$

1. Konstanta $(\alpha)$

$$
\alpha=2,259 \text { mengandung pengertian }
$$

bahwa perpotongan garis regresi pada variabel bebas (X1,X2), Nilai 2,259 juga berarti bahwa beauty advisor tidak menerapan keramahan dan pengetahuan produk maka akan memperoleh maka perusahan akan memperoleh peningkatan penjualan sebesar 2,259 satuan.

2. Keramahan (X1) terhadap peningkatan penjualan.

$$
\beta_{1}=0,140 \text { nilai mengandungs }
$$

pengertian bahwa apabila X1 
(keramahan) naik sebesar satu satuan, maka akan diikuti dengan peningkatan penjualan sebesar 0,140 satuan dengan asumsi bahwa variabel keramahan (X1) konstan.

3. Pengetahuan produk (X2) terhadap peningkatan penjualan.

$\beta_{2}=0,313$ nilai mengandung pengertian bahwa apabila X2 (pengetahuan produk) naik sebesar satu satuan, maka akan diikuti dengan peningkatan penjualan sebesar 0,313 satuan dengan asumsi bahwa variabel pengetahuan produk (X2) konstan.

\section{Uji Asumsi Klasik}

1. Uji Multikolineritas

Nilai Variance Inflation Factor (VIF) dari variabel independent memiliki nilai yang lebih kecil, atau kurang dari 10 yaitu hanya 1,227 atau nilai tolerance semua variabel lebih besar dari $10 \% \quad(0,10)$ yakni 1,227. Sehingga dapat disimpulkan bahwa model regresi dalam penelitan ini tidak terjadi multikolinieritas.

2. Uji Autokorelasi

Nilai Durbin Watson (DW) adalah 2,222 berada pada daerah diantara dU $(1,697)$ dan 4-dU(2,303), dan DW juga berada pada daerah dL $(1,602)$ dan 4-dL(2,398) sehingga dapat disimpulkan bahwa tidak bisa menghasilkan kesimpulan yang pasti.

3. Uji Heteroskedastisitas

Dari gambar Scatterplot Dependent variabel yang ada, maka dapat dilihat titik-titik tidak terdapat pola tertentu, serta titik-titik menyebar diatas dan dibawah angka nol pada sumbu Y, maka tidak terjadi heteroskedastisitas.

4. Uji Normalitas

Dari Normal P-P Plot Dependent Variabel yang ada, dapat disimpulakan bahwa Normal P-P Plot Dependent Variabel terlihat titik-titik penyebaran disekitar garis diagonal dan mengikuti arah garis diagonal, maka regresi tersebut memenuhi asumsi normalitas

\section{Uji Hipotesis}

1. Uji F(Simultan)

Pengujian untuk pengaruh variabel babas secara bersama-sama atau simultan terhadap variabel terikat dilakukan dengan menggunakan uji $\mathrm{F}$. Hasil perhitungan menunjukan nilai $F$ hitung $=32,214$. Dengan signifian 0,000 , maka diperoleh nilai signifikan tersebut lebih kecil dari 0,05. Dengan df pembilang $=2$ dan $\mathrm{df}$ penyebut $=83$ didapatkan $\mathrm{F}$ tabel 3,11. Karena F hitung $=32,214>\mathrm{F}$ tabel $=3,11$, Hal ini berarti hipotesis menyatakan $\mathrm{H}_{0}$ ditolak dan $\mathrm{H}_{1}$ diterima, jadi variabel keramahan dan pengetetahuan produk mempunyai pengaruh signifikan terhadap peningkatan penjualan.

2. Uji T (Parsial)

a. Nilai T hitung keramahan (X1) terhadap peningkatan penjualan sebesar 2,340 sementara untuk $\mathrm{t}$ tabel dengan taraf signifikan $\mathrm{a}=0,05(0,05 / 2)$ dan $\mathrm{df}=\mathrm{n}-\mathrm{k}-$ 1, yaitu sebesar 86-2-1 = 83 sebesar 1,988, maka didapat $\mathrm{t}$ tabel satu sisi sebesar 1,988. Dikarenakan nilai $\mathrm{T}$ hitung > $\mathrm{T}$ tabel, maka menunjukan bahwa diteimanya $\mathrm{H}_{1}$ yang menyatakan ada pengaruh positf keramahan terhadap peningkatan penjualan

b. Nilai T hitung dari pengetahuan produk (X2) terhadap peningkatan penjualan sebesar 5,923 sementara untuk $\mathrm{T}$ tabel dengan taraf signifikan a $=0,05(0,05 / 2$ $=0,025)$ dan $\mathrm{df}=\mathrm{n}-\mathrm{k}-1$, yaitu $86-2-1=$ 83 sebesar 1,988, maka di dapat $\mathrm{T}$ tabel satu sisi sebesar 1,988 dikarenakan $\mathrm{T}$ hitung > $\mathrm{T}$ tabel, hal ini menunjukan bahwa diterimanya $\mathrm{H} 1$ yang menyatakan ada pengaruh positif variabel pengetahuan produk.

\section{SIMPULAN DAN SARAN Simpulan}

Berdasarkan hasil dari hasil analisis danpembahasan yang telah dilakukan tentang pengaruh keramahan dan pengetahuan produk beauty advisor 
terhadap peningkatan penjualan di CV.Bin Wahab group Sugio, maka dapat disimpulkan dalam penelitian ini sebagai berikut:

1. Hasil penelitian menunjukan bahwa secara parsial variabel keramahan berpengaruh positif dan signifikan terhadap peningkatan penjualan pond's pada CV. Bin Wahab group. Hal ini dibuktikan dengan nilai thitung sebesar 2,340>t tabel sebesar 1,988 dengan nilai signifikan sebesar $0,02<0,05$. Hal ini telah menunjukan bahwa keramahan yang diberikan beauty advisor dengan baik, maka akan berdampak pada peningkatan penjualan yang semakin baik.

2. Hasil penelitian menunjukan bahwa secara parsial variabel pengetahuan produk berpengaruh positif terhadap peningkatan penjualan pond's pada CV.Bin Wahab group Sugio. Hal ini dibuktikan dengan nilai $\mathrm{t}$ hitung sebesar 5,923 > t tabel sebesar 1,988 degan nilai signifikan sebesar $0,00<0,05$. Hal ini telah menunjukan bahwa pengetahuan produk oleh beauty advisor dengan baik, maka akan berdampak pada peningkatan penjualan yang semakin baik.

3. Hasil penelitian yang telah dilakukan menunjukan bahwa kedua variabel yaitu keramahan dan pengetahuan produk secara simultan berpengruh positif dan signifikan terhadap peningkatan penjualan. Hal ini dibuktikan dengan hasil dari nilai $\mathrm{F}$ hitung sebesar 32,214>F tabel sebesar 3,11 dengan nilai signifikan sebesar $0,000<0,05$. Hal ini menunjukan bahwa keramahan dan pengetahuan produk beauty advisor yang baik akan berpengaruh kepada peningkatan penjualan.

4. Faktor yang dominan mempengaruhi peningkatan penjualan adalah pengetahuan produk, 0,313 nilai mengandung pengertian bahwa apabila X2 (Pengetahuan produk), naik sebesar satu satuan maka diikuti oleh peningkatan penjualan sebesar 0,313 satuan.

\section{Saran}

Berdasarkan hasil dari penelitian, pembahasan dan kesimpulan yang telah diperoleh, maka saran yang dapat diberikan dari peneliti yaitu:

1. Diharapkan kepada beauty advisor dapat lebih meningkatkan sikap keramahan dan meningkatkan pengetahuan produk guna menghadapi kepada konsumen pond's di CV . Bin Wahab Group dengan maksimal sehingga dapat meningkatkan penjualan lebih baik lagi.

2. Diharapkan kepada pihak PT.Unilever Indonesia Tbk, lebih mengadakan pelatihan atau pemberian materi kepada beauty advisor sehingga dapat meningkatkan kemampuan dan pemahaman produk pond's.

3. Diharapkan kepada CV. Bin Wahab group untuk mengutamakan pelayanan termasuk sikap ramah kepada konsumen, sehingga konsumen akan lebih nyaman dan terbantu saat berbelanja.

\section{DAFTAR PUSTAKA}

Ahmad, Subagyo. (2010), Marketing In Business,Mitra Wacana Media, Jakarta. Arikunto, Suharmi. (2014), Manajemen Penelitian, Rineka Cipta, Jakarta.

Badri, Muhammad. (2011), Corporate and Marketing Communication, 
Universitas Mercu Buana, Jakarta.

Djaslim, Saladin. (2014), Intisari Pemasaran dan Unsur-unsur Pemasaran, Linda Karya, Bandung.

Esther Novianty. (2017), Pengaruh Pengetahuan Produk, Kesadaraan Merek, Presepsi Nilai, Dan Atribut Produk, Terhadap Keputusan Pembelian Online Kosmetik Qweena Skincare, Jurnal, Universitas Lampung, Lampung.

Ferdinand, A. T. (2014), Metode Penelitian Manajemen, BP UNDIP, Semarang.

Hanjaya Sanny. (2016), Pengaruh Kualitas Produk, Pengetahuan Produk dan Keragaman Menu Terhadap Keputusan Pembelian Produk Capralatte, Jurnal Manajemen,Universitas Ciputra Surabaya, Surabaya.

Herianto Ari Wibowo dan Moh Fauzi. (2017), Pelayanan Konsumen, Nuha Medika, Yogyakarta.

Jusuf Soewadji. (2012), Pengantar Metodelogi Penelitian, Mitra Wacana Media, Jakarta.

Kotler, Philip dan Kevin Lane Keller. (2009), Manajemen Pemasaran, Jilid 1. Erlangga, Jakarta.

Kotler, Philip. (2014), Manajemen Pemasaran, Erlangga, Jakarta.

Kuncoro, M. P. (2013), Metode Riset untuk Bisnis \& Ekonomi Bagaimana Meneliti dan Menulis Tesis, Erlangga, Jakarta.

Liossa, David Bowen. (2020), Custumer Proactive Trainning Vs Customer Reactive Trainning Retail Store Settings : Effects On Scripts Proficiency Customer Satisfaction, And sales volume, Jurnal International,
Malhotra, Naresh K. (2014), Riset Pemasaran Pendekatan Penerapan, PT. Indeks.

Oktafiana Afifah Nur. (2016), Pengaruh Selebbriti Endors ( raisah Anriana) Terhadap Keputusan Pembelian Produk Kosmetik Pond's white Beauty, Jurnal, Universitas Islam Negeri maulana Malik Ibrahim, Malang. Rangkuti Freddy. (2014), Stategi Promosi Yang Kreatif, Penerbit Gramedia Pustaka Utama, Jakarta.

Sangadji, Etta Mamang dan Sopiah. (2013), Perlaku konsumen. Penerbit Andi, Yogyakarta.

Schiffman, Leon dan Kanuk, Leslie L. (2014), Perilaku Konsumen, Indeks, Jakarta.

Simamora, Bilson. (2011), Memenangkan Pasar Dengan Pemasaran Efektif Dan Profitabel. PT. Gramedia Pustaka Utama, Jakarta.

Sriyanto. (2015), Analisis Pengaruh Harga, Promosi, Dan Kualitas Pelayanan Terhadap Peningkatan Penjualan Tiket PT. Rosalia Indah Tour and travel di Palur Karang Anyar, Jurnal, Universitas Muhammadiyah Surakarta, Surakarta.

Steven Lu, Rohan Miler. (2019), How Social Media Communiation Combine With Customer Loyalty Management To Boots Green Retail Sales, Jurnal International, Businees School, The University of Sydne, Australia

Sugiyono. (2013), Metode Penelitian Manajemen, Alfabeta, Bandung.

Sugiyono. (2014), Statistika Untuk Penelitian Bisnis, Alfabeta, Bandung.

Sugiyono. (2015), Metode Penelitian Kuantitatif Kualitatif dan $R \& D$, 
Cetakan Kedua Puluh Dua,

Alfabeta, Bandung.

Sugiono. (2018), Metode Penelitian

Kuantitatif Kualitatif Dan $R \& D$,

Cetakan-1, Edisi Kedua,

Alfabeta, Bandung.

Supranto dan Nandan Lima Krisna.

(2012), Perilaku Konsumen,

Mitra Wacana Media, Jakarta.

Suwarman, U. (2011), Perilaku

Konsumen Teori dan

Penerapannya dalam

Pemasaran. Ghalia Indonesia,

Bogor.

Swastha, Basu, DH, dan Irawan. (2014), Manajemen Pemasaran, Liberty, Yogyakarta.

Tjiptono, F. (2014), Stategi Pemasaran, Andi Offset, Yogyakarta

Tjiptono, Fandy. (2014), Strategi Pemasaran. Cetakan Ketiga, Penerbit Andi, Yogyakarta.

Youngki Tri Wibowo. (2012), Analisis pengaruh keramahan karyawan harga dan lokasi terhadap kepuasaan pelanggan, Jurnal, Fakultas Ekonomi,Universitas Diponegoro, Semarang. 